\title{
EDUCAÇÃO PELA LITERATURA: BALZAC, CHARTIER E A COSTUREIRINHA CHINESA
}

\author{
EDUCATION THROUGH LITERATURE: BALZAC, CHARTIER AND THE LITTLE CHINESE \\ SEAMSTRESS
}

Lucelena Abrantes Ferreira

Doutora em Educação pela PUC/Rio. Docente do Programa de Pós-Graduação em Educação da UCP.

\author{
Programa de Pós-Graduação em Educação \\ Universidade Católica de Petrópolis (UCP) \\ Petrópolis - RJ - Brasil \\ Endereço: \\ Rua Humberto de Campos, 410/1403 \\ Rio de Janeiro - RJ \\ CEP: $22430-190$ \\ E-mail: \\ lucelena@terra.com.br
}

\begin{abstract}
RESUMO
Este artigo apresenta uma reflexão sobre a formação do leitor literário, com base em uma leitura do filme Balzac e a Costureirinha Chinesaํ' (Balzac et la petite tailleuse chinoise, 2002, França/China, 111 minutos, direção de Dai Sijie, roteiro de Dai Sijie e Nadine Perront), realizada a partir de conceitos desenvolvidos na obra de Roger Chartier. Ao estudar a leitura como ato concreto pelo prisma da História Cultural da leitura, Chartier considera os leitores empíricos e as práticas que organizam o acesso e o contato com os textos em determinado grupo. A formação do leitor, as suas representações e as práticas de leitura estão ligadas às regras, aos valores e às crenças da comunidade de leitores a que pertence. No contexto do filme, três jovens chineses formam uma comunidade de leitores, driblando censuras e proibições relativas à leitura determinadas pelo governo maoísta. Este artigo objetiva refletir sobre o processo de formação da costureirinha, protagonista do filme, como leitora literária, a partir de suas vivências de leitura na "comunidade dos três amigos".
\end{abstract}

PALAVRAS-CHAVE: Comunidade de leitores. Formação do leitor. Literatura.

ABSTRACT

This article presents a reflection on the formation of the literary reader, with a reading of the film Balzac and the Little Chinese Seamstress (Balzac et la petite tailleuse chinoise, 2002, France/China, 111 minutes, directed by Dai Sijie with screenplay by Dai Sijie and Nadine Perront), based on concepts developed in the work of Roger Chartier. Studying reading as a concrete act, through the prism of the Cultural History of Reading, Chartier considers the empirical readers and practices that organize access to and contact with the texts in a given group. The formation of the reader and his/her representations and practices of reading are linked to the rules, values and beliefs of the community of readers to which he/she belongs. In the context of the film, three young Chinese people form a community of readers, avoiding the reading prohibitions imposed by the Maoist government. This work seeks to understand the formation of the seamstress, the protagonist of the film, as a reader of literature, based on her experiences of reading in the "community of the three friends". 
KEYWORDS: Community of readers. Formation of the reader. Literature.

\section{A COMUNIDADE DOS TRÊS AMIGOS: LEITORES EM FORMAÇÃO}

Este artigo apresenta uma reflexão sobre caminhos de formação do leitor literário, com base em uma leitura do filme Balzac e a Costureirinha Chinesa, realizada a partir de conceitos desenvolvidos na obra de Roger Chartier.

Ao estudar a leitura como ato concreto, pelo prisma da História Cultural da leitura, Chartier considera os leitores empíricos e as "redes de práticas que organizam, histórica e socialmente, os modos diferenciados de acesso aos textos" (1988, p.122). O autor lança olhar sobre os gestos, os objetos, as posturas em torno da leitura, considerando que estes mudam com tempos e lugares. Assim, considerar a leitura como prática cultural inclui levar em conta a circunstância concreta em que se dá a aproximação com determinado texto. De acordo com Chartier, "todo leitor diante de uma obra a recebe em um momento, uma circunstância, uma forma específica e, mesmo quando não tem consciência disso, o investimento afetivo ou intelectual que ele nela deposita está ligado a este objeto e a esta circunstância" (1999b, p.70). No contexto do filme, três jovens chineses formam uma comunidade de leitores, driblando censuras e proibições relativas à leitura determinadas pelo governo maoísta. Neste artigo, a intenção é refletir sobre o processo de formação da costureirinha, protagonista do filme, como leitora literária, a partir de suas vivências de leitura na "comunidade dos três amigos".

Para o historiador francês, leitura é prática cultural que envolve apropriação, invenção, produção de significados a partir da interação entre leitor e texto. Com a noção de "apropriação", Chartier sublinha os usos contrastados do texto, enfatizando o espaço de liberdade para construção de significados por parte do leitor, articulado a suas competências, expectativas, disposições. Mas ressalta que esta liberdade não é ilimitada. Neste ponto, o autor destaca dois conjuntos de dispositivos que interferem na liberdade do leitor: as estratégias textuais e as intenções do autor, e aqueles que resultam de decisões de editores ou de limitações impostas por oficinas impressoras. Além disso, há que se considerar o fato de que todo indivíduo está inserido em um contexto social. Ele também é expressão do coletivo. A singularidade do leitor é perpassada pela influência da(s) comunidade(s) da(s) qual(is) faz parte, por seus modelos e normas. Para que se compreenda o processo de construção de significados, torna-se fundamental considerar, além das competências e das práticas do leitor, as formas discursivas e materiais do texto, o tipo de suporte e ainda os códigos e as convenções que regem as práticas da(s) comunidade(s) de leitores à(s) qual(is) pertence cada leitor singular (CHARTIER, 1988).

O filme começa com a história de Luo e Ma, dois jovens chineses urbanos que são enviados em 1971 a uma aldeia tradicional da China, fortemente apegada aos valores maoístas, para sofrer um processo de reeducação. São forçados a viver esta experiência, pois suas famílias são consideradas "reacionárias". Com a chegada dos rapazes, duas comunidades de leitores distintas passam a conviver na Montanha Fênix: a que obedece às censuras do regime; e a transgressora, formada pelos rapazes. Em meio a tensões e contrastes, surgem trocas e harmonias imprevistas.

$\mathrm{Na}$ chegada, acentuam-se diferenças: um livro que traziam na mala é queimado pelo chefe dos camponeses, pois se refere a costumes "burgueses" (para usar a categoria nativa). O violino só escapa da fogueira quando Ma toca uma música que agrada a todos. O rapaz consegue permissão para tocá-la, porque Luo mente a respeito do título, anunciando que o colega tocará uma sonata chamada "Mozart está pensando no presidente Mao". Quando o chefe pergunta o que é uma sonata, ele diz que é uma canção montanhesa. A apreensão de qualquer objeto que remeta aos costumes "burgueses", com o ritual de queima do mesmo, faz parte dos mecanismos pelos quais a liderança local tenta impor a sua concepção do mundo social, as suas representações, os seus valores e, consequentemente, o seu domínio. A representação de cultura "burguesa" como algo nocivo comanda esta prática. Ao queimar o livro, o chefe anuncia que lá eles se dedicarão ao trabalho braçal.

Da aldeia vizinha, chegam o alfaiate e a sua neta, a costureirinha. Luo e Ma se encantam com ela, apesar de a considerarem "primitiva" (categoria nativa). Riem de seu linguajar "simples". Predomina, nos rapazes, um olhar etnocêntrico, que os leva a perceber a matriz cultural da moça pela ótica da falta. Apesar dos contrastes, inicia-se uma relação de amizade entre os três. 
“A vida aqui não tem muita graça. Sempre que vou cortar lenha, vejo aviões passarem no céu, imagino como seria o mundo em outros lugares...", diz a costureirinha. "Você sabe ler?", pergunta Luo em seguida. Diante da reposta negativa, ele decide: "Vou te ensinar a ler". Assim, vai surgindo uma nova comunidade de leitores na Montanha Fênix.

Neste diálogo, ocorrido no início do filme, Luo deixa entrever sua representação de leitura como contraponto ao confinamento físico (e cultural) da costureirinha (imposto pelos costumes locais). Ler permitiria "viajar" em pensamento, conhecer outros lugares e matrizes culturais. Leitura afirma-se como possibilidade de acesso ao diferente. Literatura é a viagem possível.

Fugindo à lógica de censura e obediência que guia a comunidade camponesa de leitores, a pequena comunidade dos três leitores funda-se na lógica da transgressão, incorporada como estratégia de sobrevivência. O caminho é inevitável: não fosse pelo rompimento com a ordem dominante, a comunidade não existiria. Para este grupo, os livros proibidos pelos valores maoístas ocupam posição primordial. O reforço à cultura ocidental boicota a reeducação pretendida pelo sistema.

Enquanto a comunidade camponesa, analfabeta, não possui acervo disponível de livros, os três amigos conseguem obter alguns exemplares proibidos, furtando-os de outro reeducando (que os guardava escondidos em uma mala). Até então, devido às imposições do regime, só conheciam histórias socialistas. Por conta da limitação física do acervo, sem renovação possível, Luo, Ma e a costureirinha acabam por formar uma comunidade de leitores intensivos, lendo, relendo e contando sempre os mesmos textos. Chartier define a leitura 'intensiva' como aquela "confrontada a livros pouco numerosos, apoiada na escuta e na memória, reverencial e respeitosa" (1999a, p. 23). Para o historiador, "o leitor 'intensivo' é confrontado a um corpus limitado e fechado de textos, lidos e relidos, memorizados e recitados, ouvidos e conhecidos de cor, transmitidos de geração em geração" (1999a, p. 99). Naquele ambiente de censuras, saber textos proibidos de cor ( podendo inaugurar para eles novo suporte - a voz) é boicotar em definitivo a fogueira, garantindo a permanência dos trechos memorizados.

Animado com a aquisição do acervo, Luo afirma: “Com estes livros estrangeiros, juro que transformarei a costureirinha. Vou curá-la de sua ignorância". Revelam-se interesses e expectativas com os quais ele investirá em práticas de leitura. Luo assume uma representação corrente na cultura ocidental: livros transformam. Ma partilha desta representação da leitura como prática transformadora. Ao ar livre, após ler Balzac, ele afirma: "Sinto que o mundo mudou. O céu, as estrelas, os sons, até o cheiro dos porcos. Tudo mudou". O testemunho é de que os livros modificam a pessoa, o olhar, o mundo construído por este olhar. Com seu sotaque chinês "urbano", Ma grita o nome da heroína do livro, Ursule Mirouet, repetido pelo eco das montanhas.

O desejo de Luo parece confirmar-se tempos depois, quando o alfaiate procura os dois rapazes para fazer um pedido: "Minha neta mudou recentemente. [...] Parem de ler romances para ela. Eles não dizem a verdade. Tratem de aprender coisas úteis". A leitura de romances "burgueses", seguindo a representação partilhada pela comunidade camponesa, é nociva e inútil. O avô havia flagrado sua neta usando e mostrando um sutiã (costume ocidental) às amigas e citando um trecho de livro que sabia de cor. Diz o ancião: "Temi tanto por ela que minhas mãos tremeram. Às vezes, um livro pode afetar a sua vida inteira". O alfaiate compartilha da representação do livro como algo que inspira temor, devido, sobretudo, ao seu poder de transformação. Já para os "reacionários", o livro (especialmente os proibidos) tem tanto valor que é usado como moeda de troca, como ocorre no caso em que Ma pede um favor a um médico da cidade e oferece um de seus livros estrangeiros em pagamento. Um pedaço do romance francês copiado em seu casaco (novo suporte) serve como prova da existência do livro prometido. O trecho de Balzac que a costureirinha conta para as amigas reproduz o pensamento de Luo e Ma: “O selvagem só tem sentimentos. O civilizado tem sentimentos e idéias". Neste contexto, leitura se afirma como caminho para a civilização. Quando Ma diz ao amigo que ele conseguiu curar a costureirinha de sua ignorância, como havia prometido, Luo resume: "Ler romances para ela foi útil".

Uma das inquietações que dominam historicamente a relação com a cultura escrita aparece potencializada na comunidade dos três amigos: o temor da perda. Em um ambiente de forte censura aos livros, com risco de apreensão e destruição de qualquer um que seja encontrado, estes precisam ser escondidos. Uma caverna distante é indicada pela costureirinha para este fim, exercendo a função de guardiã do acervo. A fogueira é a figura invertida da caverna, que protege e preserva o 
patrimônio textual (CHARTIER, 1999b). A caverna-biblioteca ganha o nome de "Gruta dos Livros". Uma regra é combinada entre eles, em cuidado de preservação: só podiam retirar um livro de cada vez. Desta forma, se fossem pegos lendo, só perderiam um exemplar.

Dentro de um contexto em que o suporte livro era proibido, a iniciativa realizada por Ma de criar um suporte não usual, escrevendo trechos no forro do próprio casaco, é inventar possibilidade de ler quando, o quê e onde quiser (novas formas comandam novos usos e práticas), reduzindo o risco de confisco que o livro, suporte conhecido, oferecia. É, ainda, criação de texto afetivo, copiado "religiosamente" (termo usado por Ma), combinando trechos preferidos de livros lidos. Texto em mosaico, quase tatuagem.

Algumas práticas de leitura ganham relevo na pequena comunidade "burguesa" de leitores. O segredo é condição necessária para sua realização, já que são consideradas ilegítimas pela comunidade camponesa. Assim, suas formas revelam esforço de sobrevivência. Ma se entrega à leitura silenciosa de Balzac na cama, noite adentro, em transgressão amparada pelo sono de todos. Ele divide o quarto com Luo, o que garante alguma privacidade, apesar de não se poder trancar a porta.

Certa vez, o alfaiate pega Luo lendo para a neta: queima o livro. O chefe flagra Ma contando histórias ("reacionárias", segundo os valores maoístas) no quarto, e ameaça denunciá-lo à Secretaria de Segurança Pública, para que seja punido: "Falar! É só o que vocês burgueses sabem fazer". Apesar dos riscos, a leitura em voz alta foi a prática escolhida para driblar o analfabetismo da costureirinha, cumprindo a dupla função de comunicar o texto e ampliar formas de sociabilidade entre os três amigos (CHARTIER, 1999a, p.16).

Luo ensina a moça a escrever "eu te amo". Pede que leia várias vezes em voz alta o que escreveu. Nesta comunidade de leitores, língua e afeto se mantêm enlaçados. No fim, ao deixar os amigos e a vida na Montanha Fênix, a costureirinha afirma que quem a transformou foi Balzac (usado como metonímia para as histórias dele). Mas não há texto fora do suporte que o dá a ler (ou a ouvir) (CHARTIER, 1999a, p.17). Os romances de Balzac, Flaubert e os outros lidos em voz alta pelos rapazes vêm úmidos de humanidade e afeto, ilustrando o que Eliana Yunes chama de leitura solidária. Segundo Yunes (2002, p.37),

\begin{abstract}
As leituras solidárias ou partilhadas se dão sem pedagogismos, ao pé da cama ou em torno do fogo, ou depois de um filme na mesa de um bar, quando uma cumplicidade implícita aproxima vozes, imaginários, apreensões, dúvidas e perguntas. Basta rever o "clima" dos acalantos com suas melodias singelas e seus relatos condensados. O conforto destes toques do olhar, das ênfases e das respirações suspensas, das pausas e dos silêncios, como traduz a argúcia e sagacidade de Pennac, são quase (como um) romance. Pode não ser definitivo, mas é de impulso vital a experiência das primeiras histórias.
\end{abstract}

Ma e Luo contam por ela, costureirinha. Emprestam tom, pausa, sentimento, promovendo aproximação entre narrador e ouvinte, e entre ambos e as histórias contadas. Dá-se o contágio: podem co-mover porque os livros os movem (CHARTIER, 1999a, p.25). A ligação entre texto e voz é amparada em afetos. Ma chega a afirmar: "Enquanto lia, me via no lugar do marido, e depois como os amantes de Emma. A costureirinha era a minha Bovary". Após assistir a um filme nortecoreano (ouvido por ela anteriormente na voz dos dois rapazes), a moça diz a Luo: "Na verdade, não é tão bom como quando você conta".

A prática de leitura partilhada é adotada pelos dois rapazes claramente com fins de socialização, obedecendo à promessa feita por Luo (e assumida também por Ma) de resgatar a costureirinha "de sua ignorância", por meio do acesso a outras matrizes culturais, menos "primitivas" (categorias nativas). O sucesso da empreitada deixa-se entrever, pouco a pouco, nas mudanças de sotaque, vocabulário, ideias, valores, gestos, atitudes da moça, culminando com a saída física da costureirinha da Montanha Fênix, em movimento de recusa ao confinamento em suas raízes culturais. Reeducação consumada.

Em um dado momento, preocupado com a influência de Luo e Ma sobre sua neta, o avô decide hospedar-se no quarto dos rapazes. Esta decisão acaba por promover proximidade. O ancião "morde a isca" e começa também a ouvir histórias. Durante nove noites seguidas, Ma narra um livro de Alexandre Dumas. No seu trabalho de costura, o alfaiate desdobra apropriação dos textos, deixando vestígios da leitura noturna (símbolos franceses) povoarem suas roupas, transformadas. Como ele.

A comunidade dos três amigos ganha o seu D'Artagnan. 
Como parte de seu processo de reeducação, Luo e Ma são enviados à cidade para assistir a um filme "revolucionário", e recebem a missão de contá-lo aos membros da comunidade camponesa. O chefe evidencia suas expectativas: estão em "missão política". A comunidade de camponeses caracteriza-se por um forte controle do acesso aos textos (em qualquer linguagem). Assim, é o 'chefe' que designa que filme será visto e narrado.

As narrações feitas por Luo e Ma intensificam empréstimos e intercâmbios entre matrizes culturais diferentes e suas práticas, valores, representações. Da primeira vez, assistem a um filme da Coréia do Norte. Na volta, os camponeses se encantam com a narração dos rapazes, que mostram suas qualidades como contadores de histórias. Incluem até mesmo neve feita de cascas de arroz (ressignificam elemento típico da cultura local), promovendo experiências sensoriais na plateia. Nas vezes seguintes, sem que os ouvintes saibam, eles não narram os filmes vistos, mas sim livros "burgueses" lidos em segredo. Oferecem textos ocidentais "disfarçados" de filmes "revolucionários", revertendo o sentido pedagógico da "missão política". O papel de (únicos) mediadores alargava a liberdade de intervenção no texto.

Luo e Ma transportam para a comunidade camponesa uma prática central da sua comunidade "burguesa" de leitores: a narração de histórias de livros ocidentais. De que forma organizam esta prática? Para os camponeses, os livros são contados de cor (em versão construída a partir da leitura prévia), já que o suporte livro não podia aparecer. Procuram antecipar as expectativas e as competências de seus receptores, realizando um trabalho de adaptação do texto a regras e convenções da comunidade de leitores montanheses (CHARTIER, 1988, p.129). Isto é feito por meio de pequenas intervenções iniciais na apresentação. Usam o texto como instrumento de aculturação, ampliando a liberdade de leitura dos camponeses para além dos textos e autores permitidos, sem que eles tomem conhecimento. Ao intervir no texto como desvio às proibições, gerando aceitação do mesmo, os rapazes renovam a dialética entre imposição (de certas leituras, textos, autores) e apropriação, entre a liberdade refreada do leitor e os limites transgredidos (CHARTIER, 1999a, p.8).

Luo e Ma promovem transformação nos textos narrados, com livre inserção de símbolos aceitos e valorizados pela cultura maoísta - geralmente nos comentários iniciais sobre a história que será contada. Mentem, por exemplo, sobre a nacionalidade do suposto "filme", que passa a ser proveniente de países socialistas. Movimento de apropriação dos textos, diminuindo risco de censuras (explícitas e internas) dos receptores à história.

Pode-se considerar que, guardadas as peculiaridades, os dispositivos formais e materiais introduzidos por Luo e Ma nos textos são da mesma ordem das "transformações 'tipográficas' operadas pelos editores da bibliothèque bleue nas obras de que se apropriaram" (CHARTIER, 1999a, p.21). A busca é de "adequação" ao novo público pretendido, gerando aceitabilidade. Em ambos os casos, busca-se "inscrever o texto numa matriz cultural que não é a dos destinatários originais" (CHARTIER, 1999a, p.21). Ao transformar as formas e os dispositivos por meio dos quais os textos eram propostos, Luo e Ma criaram novos públicos e novos usos para os textos apropriados.

Assim Luo inicia a segunda narração para os membros da comunidade "revolucionária": "Hoje, nós Ihes contaremos um filme da Albânia". O chefe explica aos camponeses que a Albânia é "uma grande amiga da China", e pergunta: "É bom filme?". "O melhor que já vi. [...] A protagonista deste filme albanês se chama Ursule Mirouet. É um nome bastante exótico. Vamos repeti-lo juntos?". Todos repetem o nome da protagonista do livro francês. Ma continua: "O diretor chama-se Balzac". E todos repetem: Balzac! Assim, o rapaz coloca na voz dos camponeses o autor-paradigma da sua comunidade de leitores, em harmonia súbita.

A estratégia de intervenção, combinada com a qualidade da narração (devida também ao envolvimento dos narradores com os textos), obtém êxito. É inegável o interesse que conseguem despertar com as músicas e as histórias oferecidas aos camponeses. Durante a narração dos filmes e dos livros, a mobilização da plateia evidencia-se no constante choro observado ou, ainda, na ansiedade demonstrada pelo início da história ou por algum de seus desfechos (evidenciada, por exemplo, durante as pausas e os silêncios do narrador). Sub-repticiamente, inaugura-se, entre os camponeses "revolucionários", contradição entre recusa e aceitação dos textos proibidos. 
Na comunidade "revolucionária", o viés do controle exercido sobre os textos é político. Censurase tudo o que seja contrário aos valores e à ordem maoísta, destacando o papel pedagógico e disciplinador dos textos (filmes, músicas, etc.) permitidos. A narração dos filmes, como prática coletiva de leitura, facilita o controle. Assim, as autoridades "pensam regular as condutas e as maneiras de modelar os espíritos" (CHARTIER, 1999a, p.25). Mas a leitura é, "por definição, rebelde e vadia" (CHARTIER, 1999a, p.7). Os leitores camponeses se desenham na relação tensa entre limitações e liberdades inéditas, involuntárias, inaugurais. A despeito de tantos contrastes, é curioso observar que membros das duas comunidades comungam prazer pela leitura dos mesmos textos. Roupas novas para todos.

\section{MEMÓRIAS DE LEITURA}

Vinte anos passados da saída da Montanha Fênix, os dois amigos se encontram e assistem, juntos, a uma filmagem do local feita por Ma. Em meio a memórias e saudades, ambos declaram o amor que sentiam pela costureirinha. Os dois, separadamente, tentaram encontrá-la, mas não conseguiram. Ao ver a Gruta dos Livros no filme, Luo afirma que parece ouvir gente falando lá dentro. Ma confirma que, ao filmá-la, teve a mesma impressão e ficou assustado. "Quem era?", pergunta Luo. "Eram as nossas vozes. Mais de vinte anos atrás".

De acordo com Chartier, "leitura não é só uma operação abstrata de intelecção, ela é engajamento do corpo, inscrição num espaço, relação consigo e com os outros" (1999a, p. 16). O espaço símbolo da comunidade dos três amigos leitores foi, sem dúvida, a caverna. Espaço de proteção, de sociabilidades, de práticas solidárias de leitura. A oralidade moldava os encontros na biblioteca improvisada, já que a mediação da voz era, para a costureirinha, a única garantia de acesso aos livros.

Diz Eduardo Galeano, em um conto chamado Janela sobre a Memória: “A luz das estrelas mortas viaja, e pelo vôo de seu fulgor nós as vemos vivas. A viola, que não esquece quem foi seu companheiro, soa sem que seja tocada por mão alguma. Viaja a voz, que sem a boca continua" (1994, p. 312). Assim, a caverna conservou livros e vozes. E a costureirinha, nos longes do seu destino, sugere fulgores múltiplos.

\section{REFERÊNCIAS}

BALZAC et la petite tailleuse chinoise. Produção de Les Films de la Suane, TF1 Films Productions. Direção de Dai Sijie, roteiro de Dai Sijie e Nadine Perront. São Paulo: Europa Filmes Distribuidora, 2002, França/China. DVD (111 minutos): NTSC, son., color., legendado, port.

CHARTIER, Roger; ARIÈS, Philippe (Orgs.). História da vida privada: da Renascença ao Século das Luzes. São Paulo: Companhia das Letras, 1991, v. 3.

CHARTIER, Roger. A história cultural: entre práticas e representações. Rio de Janeiro: Bertrand Brasil; Lisboa: Difel, 1988.

A ordem dos livros. Brasília: Ed. Universidade de Brasília, 1999a.

A aventura do livro: do leitor ao navegador. São Paulo: UNESP, 1999b.

DAUSTER, Tania. Representações sociais e educação. In: CANDAU, Vera Maria (org.). Linguagens, espaços e tempos no ensinar e aprender. Rio de Janeiro: DP\&A, 2001.

GALEANO, Eduardo. As palavras andantes. Porto Alegre: L\&PM, 1994.

PENNAC, Daniel. Como um romance. Rio de Janeiro: Rocco, 1995.

YUNES, Eliana. Leitura, a complexidade do simples: do mundo à letra e de volta ao mundo. In: Pensar a leitura: complexidade. Rio de Janeiro: Ed. PUC-Rio; São Paulo: Loyola, 2002. 
Ficha catalográfica do filme. Título original: Balzac et la petite tailleuse chinoise. Gênero: Drama. Duração: 111 min. Ano de produção: 2002. Tipo: Longa-metragem / Colorido. Nacionalidade: França/China. Distribuidora: Art Films. Produtora(s): Les Films de la Suane, TF1 Films Productions. Diretor: Sijie Dai. Roteiristas: Sijie Dai, Nadine Perront. Elenco: Xun Zhou, Kun Chen, Ye Liu, Shuangbao Wang, Zhijun Cong, Hong Wei Wang, Xiong Xiao, Zuohui Tang, Wei Chen, Tianlu Chen, Qing-yun Fan.

Artigo recebido em 27/04/2012

Aprovado em 14/09/2012 